\title{
Skills Gap - A Strategy for Increasing Knowledge Worker Supply \& Demand
}

\author{
J. Gregg Whittaker, Ph.D. ${ }^{a}$, Gerald Williams, Ph.D. ${ }^{b}$ \\ a Professor, William Jewell College; Managing Member, Archos Capital Partners whittakerg@william.jewell.edu \\ b Managing Member, G.Williams Consulting; Managing Member, Direct Service Works gerry@gwilliamconsulting.com
}

\section{A R T I C L E I N F O}

Received: 02-06-2016

Accepted: 15-07-2016

Available online: 29-09-2016

Keywords:

Skills Gap, Knowledge

Worker, Economic Wedge, Inefficient Equilibrium, Job-

Ready Professionals.

JEL Classification:

D01, D50, I21, J44

\section{A B S T R A C T}

The U.S. Economy has been and continues to be burdened with a "Skills Gap" where the skills of the available workforce are mismatched with the skilled talent needs of employer. The skills gap is especially evident among knowledge workers. Millions of people in the US are looking for jobs while millions of skilled jobs remain open. The unemployed and the underemployed in general do not posess the professional skills necessary for the jobs that are available. The conundrum is this recognized shortage of skilled knowledge workers has not led to the expected increase in salaries traditional economic analysis would suggest. This paper explains the true economic analysis of the skills gap in terms of an economic "wedge" that supresses knowledge worker saleries in the face of worker shortages. The paper recognizes a systemic disharmony between the momentum of traditional higher education and the rapidly changing needs and demands for professional skill sets in the marketplace. Traditional academic institutions are not predisposed to creating job-ready professionals that meet market needs, and private sector businesses are not positioned to fill the professional education, training and development gaps that exist. Significant opportunities exist to reposition the players to cerate opportunities for both academic intuitions and private sector companies to address the skills gap problem efficiently and effectively.

This is an open access article under the terms of the Creative Commons Attribution License 4.0, which allows use, distribution and reproduction in any medium, provided the original work is properly cited.

DOI: http://dx.doi.org/10.18533/job.v1i4.42

ISSN: 2380-4041(Print), 2380-405X(Online)

Despite 8.3 million people looking for jobs in the U.S. (July 2015), there are 5.4 million jobs currently open ${ }^{1}$. But how can this be? CareerBuilder.com reports ${ }^{2}$, "...more than half (54 percent) of employers currently have open positions for which they can't find qualified candidates..." While good-paying jobs exist, many of those still looking for jobs (as well as many who have simply given up the search) lack the skills and training to fill them.

We define this mismatch between what employers want and what those looking for work can do as the "Skills Gap." And this gap is expected to increase. A recent study from researchers at Georgetown University ${ }^{3}$ projects there will be 55 million new jobs by 2020 for which there will be a growing need for more skilled workers with

\footnotetext{
1 Economic New Release, Bureau of Labor Statistics, July 2 and July 7, 2015 respectively

2 CareerBuilder.com_March 2014 report

3 "Recovery: Job Growth and Education Requirements Through 2020", Georgetown University, June 26, 2013
} 
the necessary education and training to meet the demand. Moreover, PwC's $18^{\text {th }}$ Annual Global CEO Survey (2015) identifies the "availability of key skills" as among the top business threats to future economic growth.

\section{THE SKILLS GAP EXACERBATES UNEMPLOYMENT}

Nearly 4 million Americans could go back to work with the right training. Closing the skills gap would put these individuals to work, reducing unemployment by an estimated 2.5 percentage points.

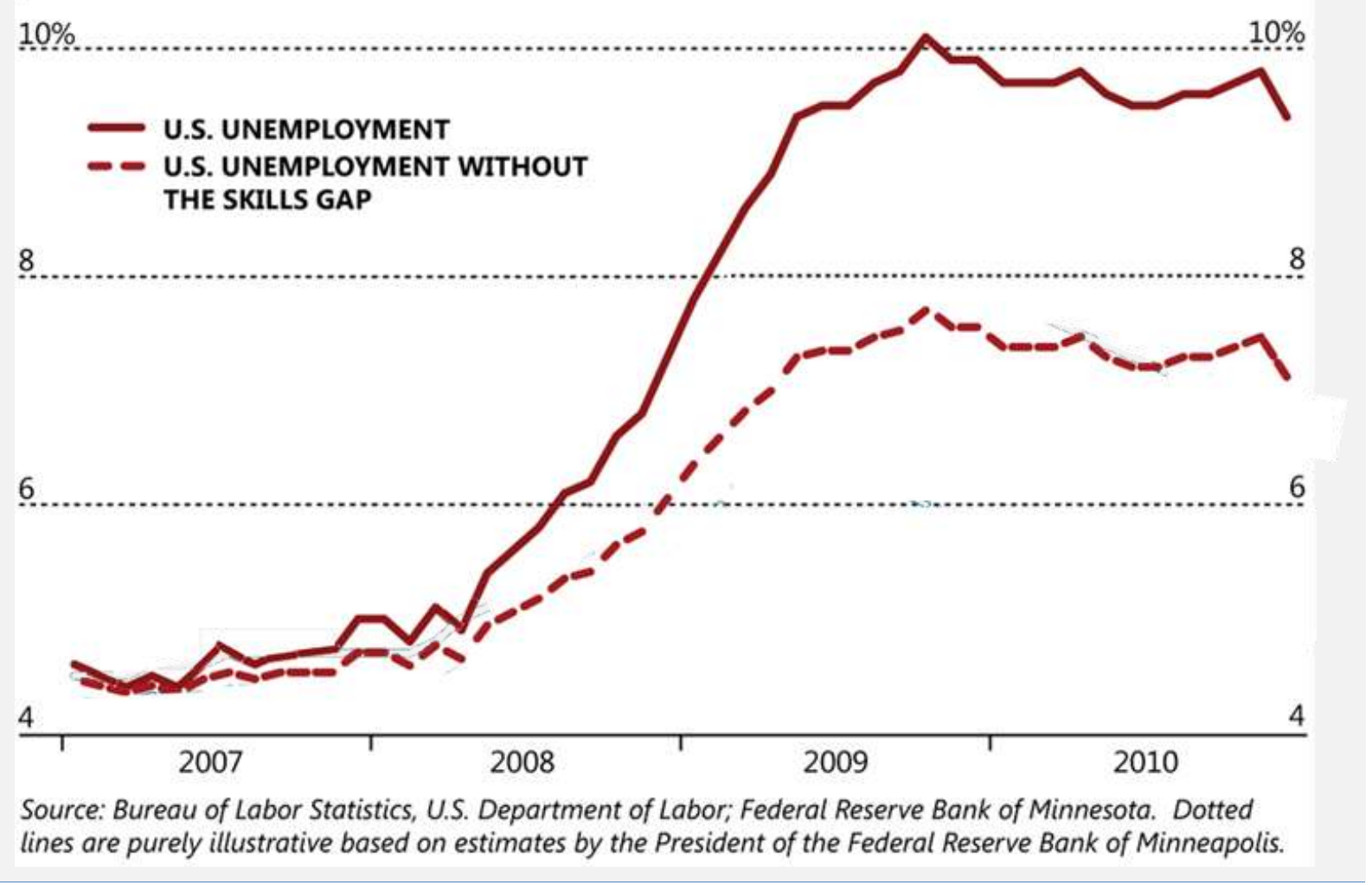

The growing demand for IT professionals, as one example of the knowledge worker skills gap, has drawn a great deal of attention. The White House launched a program in 2009 to train and prepare 100,000 new teachers to support science, technology, engineering, and math (STEM) by 20194 . This $\$ 700$ million ongoing effort is intended to address a critical skills gap, but six years later, the demand for even entry-level IT professionals is still not being met. An InformationWeek article ${ }^{5}$ asserts that a shortage of workers with skills in software engineering, information security, and "big data" will cause a significant spike in H-1B visa demand this year. In other words, despite millions of out-of-work U.S. citizens, U.S. business is forced to hire foreign workers possessing the necessary skills, with the demand for these foreign workers far exceeding the supply.

There exists an opportunity for universities and other educational institutions, including private sector, for-profit training programs, to pivot in order to meet this growing global need.

\footnotetext{
${ }^{4}$ http://www.whitehouse.gov/issues/education/k-12/educate-innovate

5 http://www.informationweek.com/strategic-cio/team-building-and-staffing/h-1b-visa-demand-spike-predicted/d/d$\underline{\mathrm{id} / 1127658}$
} 


\section{$1.0 \quad$ Knowledge workers}

There is no single, accepted definition for "skilled labor", especially when contrasted against "professionals". In the past, any occupation that required some degree of skill or training, but did not require a college degree had been classified as skilled labor. However, employers are increasingly demanding more and more from all workers, and the distinction between skilled and professional workers is becoming blurred. Regardless of how we define or contrast these groups, the skills gap problem exists and is growing for both skilled and professional workers.

We commonly associate skilled laborers with electricians and plumbers as well as those in the repair and maintenance industries. It is usually accepted that skilled laborers require less education and training than professionals such as doctors, lawyers, engineers and architects. Traditionally, the distinction was that skilled laborer talents were primarily physical and the mental skills required of such laborers did not require extensive critical thinking.

Today's workplace is increasingly characterized by self-directed teams of professionals and skilled workers working together as a single unit. Since so many jobs are now team jobs, from application development firms striving to produce that next killer mobile application to veterinary medicine clinics helping treasured pets survive medical emergencies, it is difficult to separate out the professionals from the skilled workers. It is even more difficult to know what education, knowledge, specialized training, certifications, and licenses are actually necessary for the team roles being played effectively.

Therefore, instead of distinguishing one group from another, we combine skilled laborers and professionals into a single category called "knowledge workers." It is clear that the amount of specialized expertise required of knowledge workers is increasing. Even the most mundane products and services provided by these workers now depend on high-technology components and systems demanding more and more preparation and greater knowledge and mental skills from the worker. This shift has generally been considered an improvement in terms of the productivity and the standard of living for knowledge workers. However, the current unemployment and labor participation rates suggest that a growing number of workers have not been keeping pace with these changes.

\section{$2.0 \quad$ The skills gap debate}

Though the demand for college graduates rebounded after the recent Great Recession, their rate of unemployment is still higher than prerecession levels ${ }^{6}$. This is not to say that recent grads are not getting jobs. In fact, their unemployment rate has fallen to just over $5 \%$, down from a peak of slightly more than $7 \%$ in 2011 . And this is less than half the rate of young workers who do not have a bachelor's degree. But many recent grads are underemployed, working in jobs that don't require degrees. Shockingly, the unofficial "underemployment rate has been on the rise since 2003 and now stands at 46\%."7

Another way of assessing the situation for recent college graduates is to look at student loan default rates. Both the underemployment situation as well as concerns about total student loan-related debt and the growing number of student loan defaults (nearly doubling from its low in $2004^{8}$ ) suggests recent graduates are having an increasingly difficult time finding work that pays them what they need. ${ }^{9}$ All this supports the existence of a growing skills gap.

Traditional economic analysis, on the other hand, argues the "macroeconomic data" to support the claim of a skills gap is just not there. Specifically, if there were truly a shortage of knowledge workers, one would expect to see an increase in salaries paid for such workers.

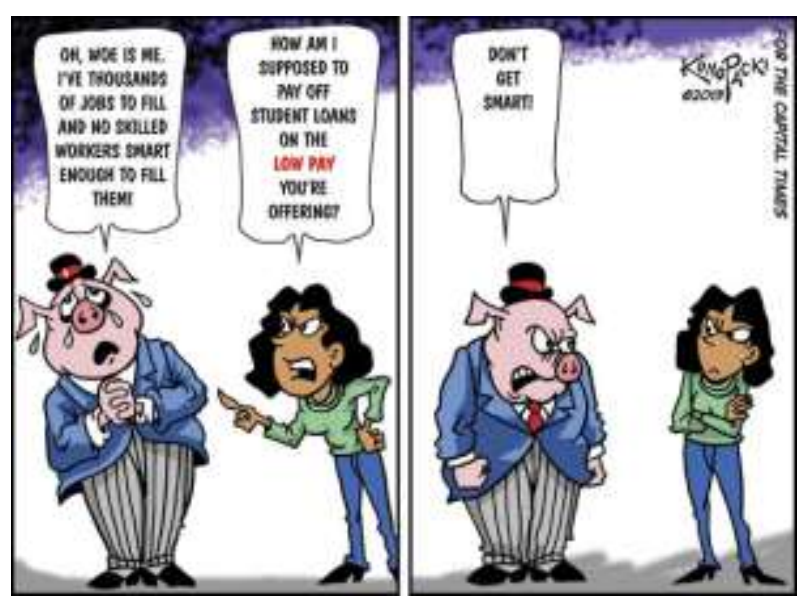

\footnotetext{
6 http://www.bls.gov/opub/mlr/2013/02/art1full.pdf

7 http://money.cnn.com/2014/09/04/news/economy/college-grads-underemployed-but-degree-worthit/index.html?iid=EL

8 http://febp.newamerica.net/background-analysis/federal-student-loan-default-rates

9 http://www.huffingtonpost.com/2013/09/30/student-loans-default n 4019806.html
} 
Figure 1: Labor Shortage

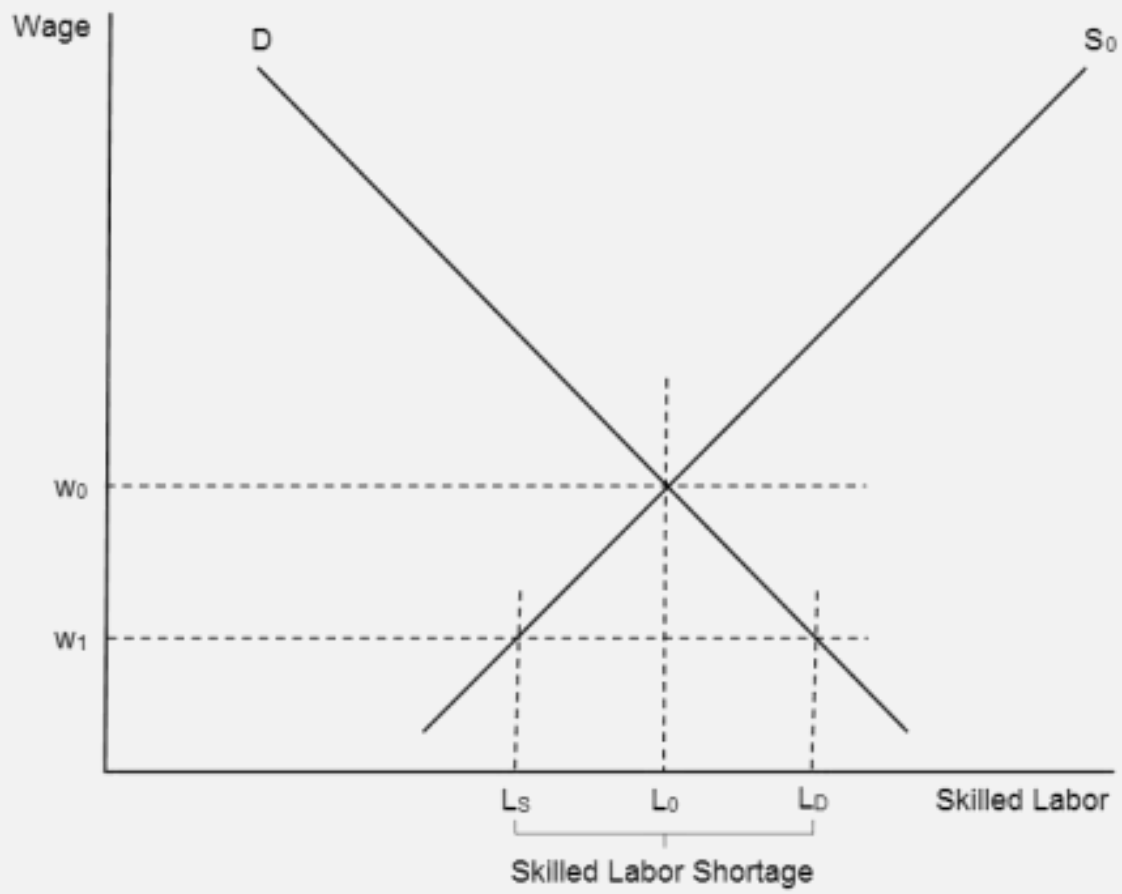

Figure 1: Labor Shortage

Figure 1 illustrates a typical knowledge worker shortage depicted in economic terms. At a wage rate of w1, the quantity of knowledge workers demanded $\left(\mathrm{L}_{\mathrm{D}}\right)$ exceeds the quantity of workers supplied (Ls). The resulting shortage would ordinarily put upward pressure on wages, thereby increasing the quantity of knowledge workers supplied while decreasing the quantity of workers demanded. This process would normally continue until the shortage is eliminated at the wage of $\mathrm{w}_{0}$ and quantity of knowledge workers supplied and demanded of $\mathrm{L}_{0}$.

The problem is that, contrary to this traditional economic analysis, wages are not rising ${ }^{10}$ and the skilled labor shortage is not dissipating. Rather, the skills gap is growing. And by some estimates the United States will face a shortage of at least 14 million skilled workers by $2020^{11}$.

So is there really a skills gap, or (1) is big business just unwilling to pay what the market requires for truly skilled and competent U.S. workers or (2) is the traditional educational system unwilling or incapable of preparing people with the skills required to be as productive as necessary in the workplace?

\subsection{Analysis of the skills gap}

The question is: Why are wages not rising as expected in the face of a significant shortage of skilled workers? The answer is that the typical understanding of the skilled labor market and the source of a labor shortage as demonstrated in Figure 1 does not consider the "economic wedge" that exists between wages received by employees and the actual costs paid by the employers.

In Figure 2 (as in Figure 1) So represents the supply curve for skilled labor from the perspective of wages received by employees, while $S_{1}$ represents the supply curve for skilled labor from the perspective of costs paid by employers. The difference between the two is the cost to employers of training employees who, while educated, do not possess the skills to be as productive as is necessary in the workplace.

Instead of an actual "shortage" in the classical sense, we see a market at equilibrium - albeit an inefficient equilibrium. At a wage rate of $\mathrm{w}_{1}, \mathrm{~L}_{1}$ skilled workers are willing to work. And at wage rate of $\mathrm{w}_{1}$ plus a cost for training of $\mathrm{TC}_{1}$, employers demand $\mathrm{L}_{1}$ such laborers. As a result, equilibrium is achieved. No upward pressure

\footnotetext{
${ }^{10}$ Pew Research Center, "For most workers, real wages have barely budget for decades", October 9, 2014. http://www.pewresearch.org/fact-tank/2014/10/09/for-most-workers-real-wages-have-barely-budged-for-decades/

11 “Do We Have the Grit to Close the Skills Gap?” LinkedIn. N.p., 31 July 2013. Web. 03 Dec. 2013, https://www.linkedin.com/pulse/20130731045642-2607450-do-we-have-the-grit-to-close-the-skills-gap
} 
exists on wages and the market remains in this state of inefficient equilibrium. Instead of seeing movement toward an efficient equilibrium, we observe a stubborn and growing "recession" of sorts for skilled workers driven by a persistent and growing skills gap.

$\mathrm{TC}_{1}$ is the cost differential between the compensation level $\mathrm{L}_{1}$ skilled workers are willing to accept and the actual cost employers are willing to pay for those $\mathrm{L}_{1}$ skilled workers. In other words, $\mathrm{TC}_{1}$ is the economic wedge between employee wages and employer costs and is the embodiment of the systemic inefficiency.

\section{Figure 2: The Economic Wedge}

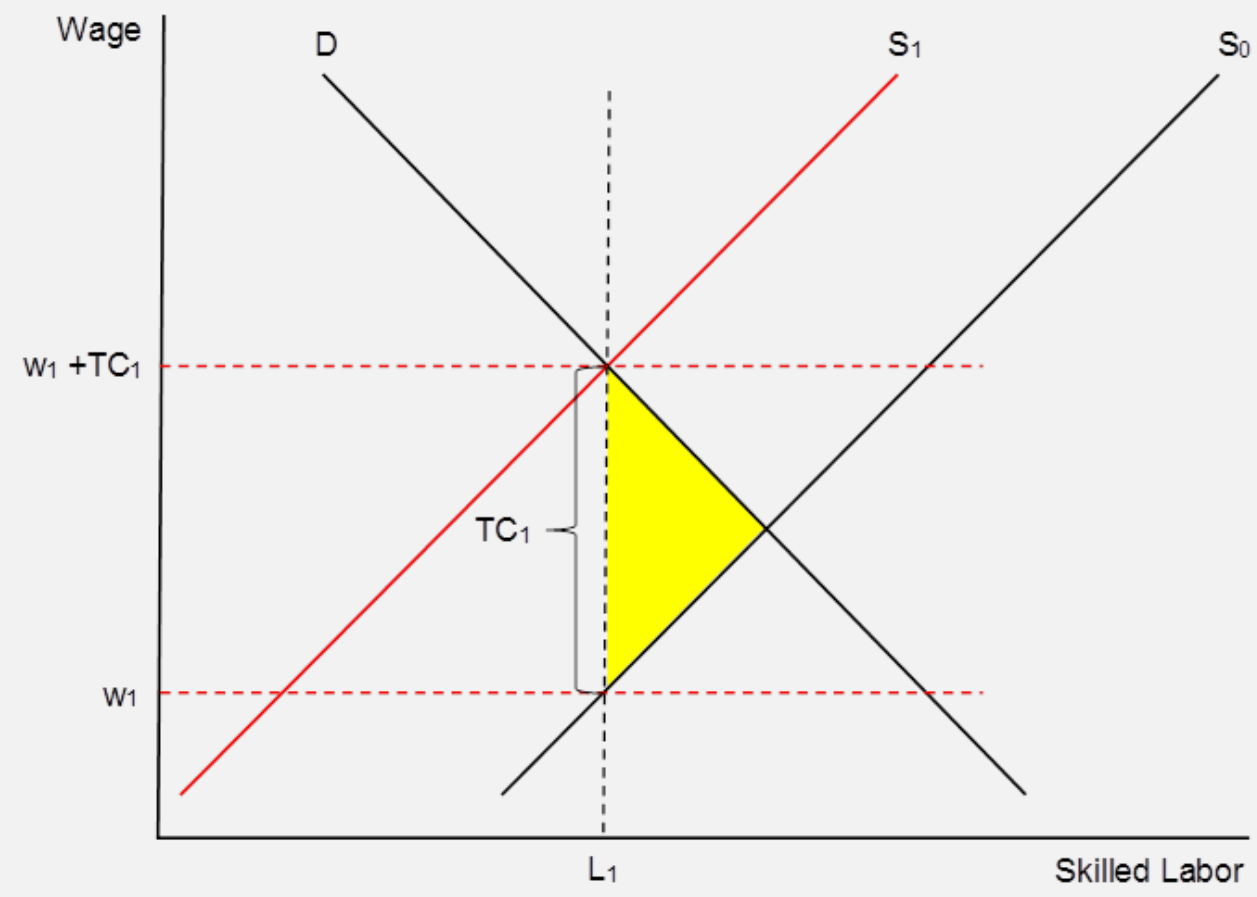

Figure 2: The Economic Wedge

More explicitly, $\mathrm{TC}_{1}$ represents the Transition Cost of preparing educated workers to be job-ready. The skills gap is a direct result of the available work force not being capable of performing at the level of proficiency required by employers for the available roles. The important point is that under the current circumstances, college graduates may be "well-educated" but they are not, in many circumstances, "job-ready." As a result, the employers and/or the workers are forced to spend significant resources $\left(\mathrm{TC}_{1}\right)$ in time and money beyond the typical educational experience to adequately prepare educated yet unqualified workers.

\subsection{Impact of closing the skills gap}

This skills gap, which is already engulfing certain industries, will soon lead to a nationwide economic meltdown unless we take action, warns Edward E. Gordon in his book, "Future Jobs: Solving the Employment and Skills Crisis"12. Business leaders are calling for government to prioritize initiatives that help foster a skilled workforce, as more than half of CEOs around the world (58\%) say a lack of key skills is hampering their growth prospects ${ }^{1}$. If the readiness level of skilled labor being provided to the market represented by supply curve So were better matched with the skill level criteria required of labor represented by the supply curve $S_{1}$ then the transition costs $\left(\mathrm{TC}_{1}\right)$ would be reduced, and the skills gap virtually eliminated. Theoretically this could eliminate or more practically significantly reduce the transition costs of preparing job-ready candidates. Figure 3 illustrates this point. 
Figure 3: Declining economic wedge

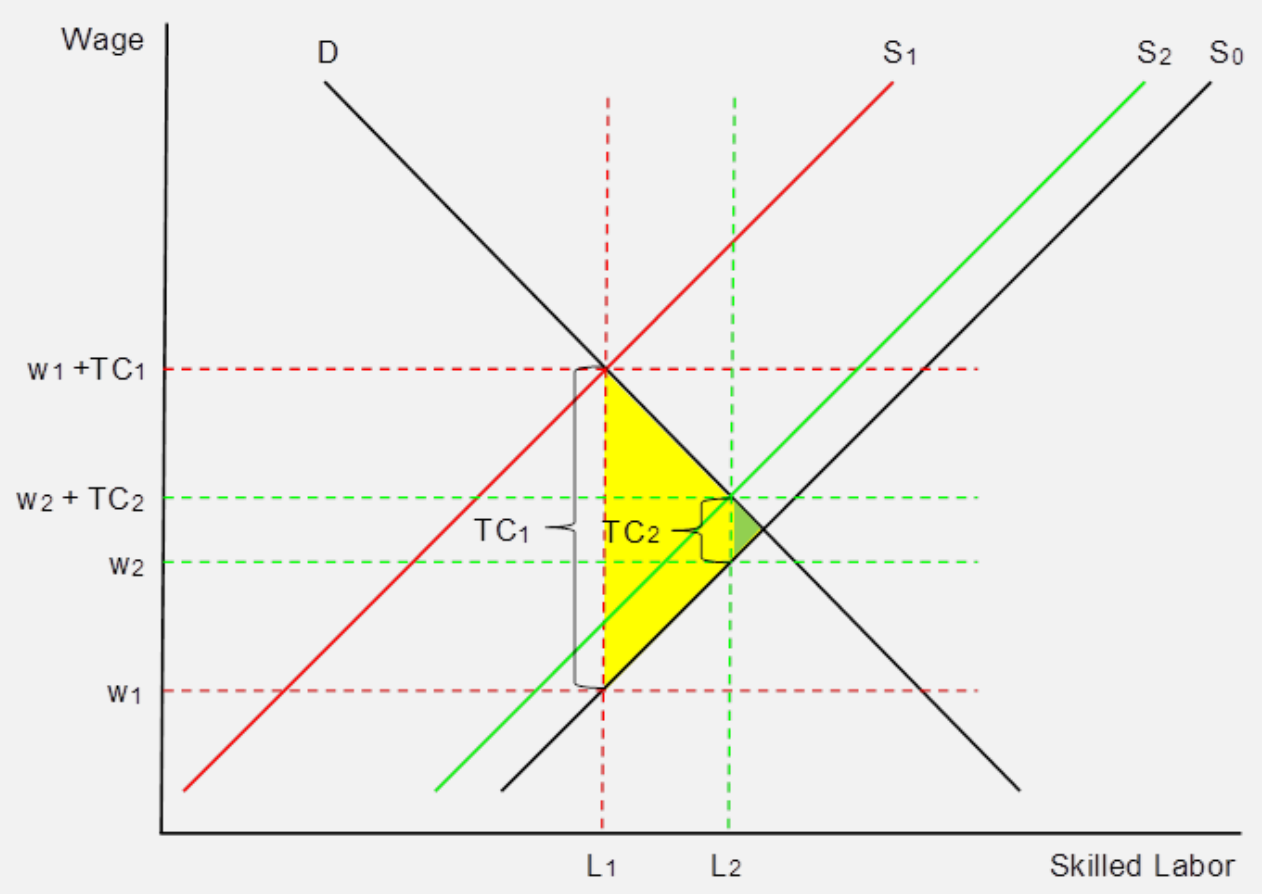

Figure 3: Declining Economic Wedge

In Figure 3, S2 represents a supply curve where, from the perspective of the employer, the labor being supplied to the market represented by $\mathrm{S}_{0}$ is more specifically job-ready and the transition costs have been reduced from $\mathrm{TC}_{1}$ to $\mathrm{TC}_{2}$. The net effects are employee wages rise (from $\mathrm{w}_{1}$, to $\mathrm{w}_{2}$ ), employer costs are reduced (from $\mathrm{w}_{1}+\mathrm{TC}_{1}$ to $\mathrm{w}_{2}+\mathrm{TC}_{2}$ ) and economic activity rises as the number of skilled jobs increase (from $\mathrm{L}_{1}$ to $\mathrm{L}_{2}$ ).

Figure 4: Increasing demand

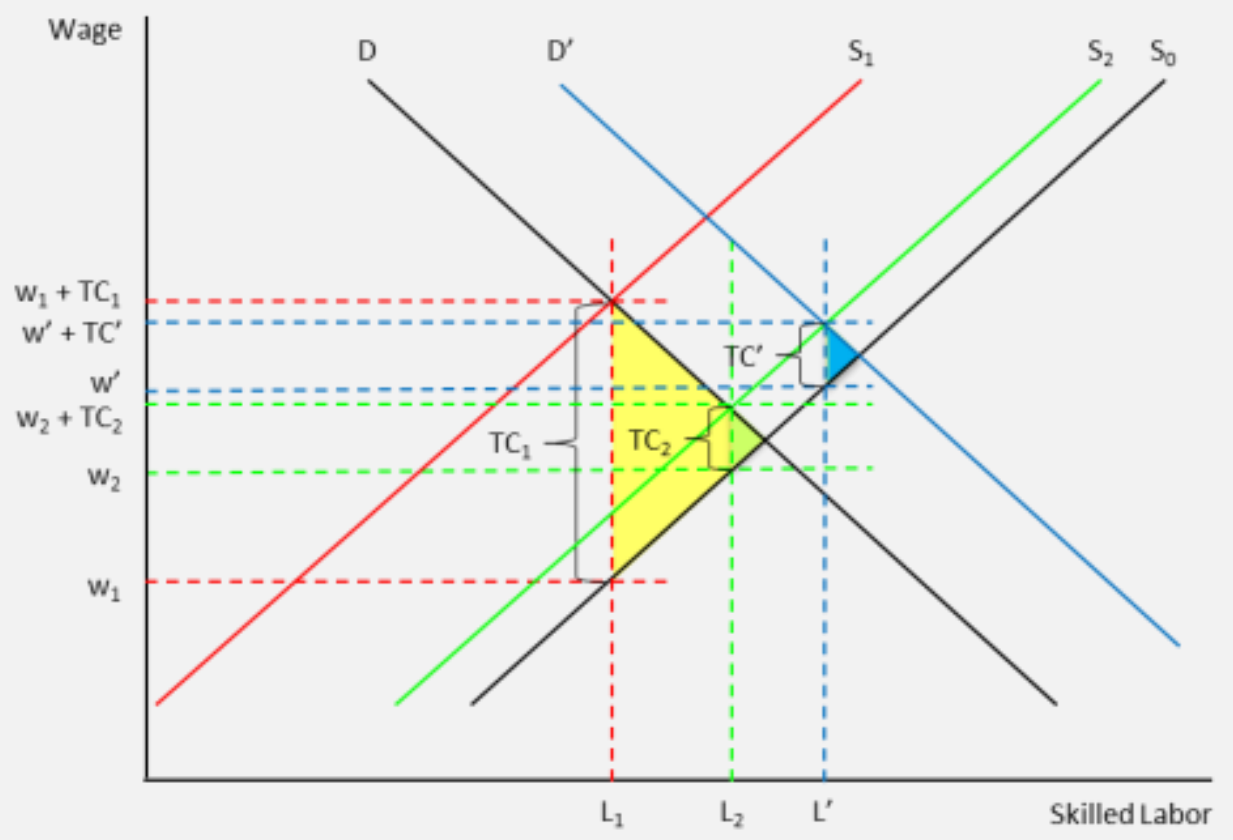

Figure 4 - Increasing Demand

And even this does not fully describe all of the benefits of a more job-ready, skilled labor force, because we have ignored the impact on demand. Demand is directly related to worker productivity, which increases with skill level. So a better-prepared work force will also drive increased demand, leading to even more jobs ( $\mathrm{L}_{2}$ to $\left.\mathrm{L}^{\prime}\right)$ and higher wages (w2 to $\left.w^{\prime}\right)$. 
Closing the skills gap is easier said than done. The combination of (1) stagnant wages (due in part to a historically weak economic recovery), (2) growing technical requirements of the workforce, (3) a lack of job-ready candidates among recent graduates and (4) rising college costs has created catch-22 situation for employers and employees alike. Most employers lack the resources to provide quality on the job training. Colleges and Universities have a comparative advantage in educating a skilled work force, but most of them struggle with implementing the changes required for their curricula to keep pace with the ever-changing needs of a dynamic workplace. And recent college graduates are caught in the middle, often lacking the skills necessary to effectively compete, commanding wages lower than expected and saddled with burgeoning college debt.

\subsection{Addressing the skills gap - An historical perspective}

\subsection{When business takes-on the responsibility}

Following World War II, it was common for businesses to take on the burden of providing workers with the knowledge, skills, and behaviors required for success. The demand for workers far exceeded the supply of highly qualified workers and the only way to take advantage of the economic boom the United States was experiencing was to hire as best you could and then provide internal training and mentoring.

While some corporations established elaborate apprenticeship and rotation programs as well as internal "universities", it was more common for firms to offer On-the-Job Training (OJT) programs where proven insiders would work with and "train" new hires. Other tactics focused on only hiring the very best, targeting just the top $10 \%$. And when it was clear that the need was greater than an exclusive hiring protocol could provide, others tried the tactic of "hire fast and fire fast." The idea here is to give candidates a chance to prove themselves. A variation of this model is to hire more than what is needed and cut the low performers (e.g. the bottom 10\%) in an annual performance review process.

OJT is also a mixed bag with successes that are not typical of most implementations. At the heart of the problem with OJT is the truth that not everyone is a good teacher. Ask most anyone how many great teachers they have had in their learning experience. The common answer is a number that can be counted on one hand. Being a good teacher is not easy, and yet very few firms that claim to provide their workers with On-the-Job Training spend any time preparing their trainers or providing time off from their regular duties to train or provide feedback. While some "trainers" may take their OJT assignments seriously and do a credible job, many do not and the training is inefficient and chaotic.

The true commitment to training as a crucial corporate strategy is revealed when slowdowns occur. Training budgets are cut. In most organizations, training and external consultants are typically the first things to go, suggesting a lack of faith from senior leadership that these investments will provide adequate return. The root of the problem is that few organizations achieve real benefit from training classes and many leaders conclude the real value of these activities to "show an interest" in their workforce as opposed to actually achieving productivity or development gains. When training outcomes are not seriously evaluated and assessed, there is little incentive for either the trainers of the students to improve.

Too often "training sessions" only require attendance to earn a certificate of completion. Tests and quizzes (typically multiple choice and short answer) are used in some case, but it is clear that employers' needs go far beyond the accumulation of testable knowledge. It is rare for corporate training to require students to produce real-world work products and deliverables. As a result, there is little chance that true skills development will be achieved in this process.

When students are asked to produce deliverables in training, the work is rarely done in a realistic context with professional feedback. Seldom is there an opportunity for the student to learn about the longer-term consequences of various decisions and actions in the context of the real world.

Some of the "better" training programs focus on delivering technical knowledge and attempting to demonstrate a student's ability to apply the knowledge, all-be-it in isolation. Truly useful education and training must ensure that not only can a worker do a job, but it must also ensure the worker is able to distinguish between situations where technologies and tools can be used effectively under varying circumstances. This is very difficult to achieve, without significant dedication to trainer/teacher preparation for the unique needs and current capabilities of this group of students or employees.

There are, however, notable exceptions where true skills are regularly and predictably developed. Apprenticeship programs in many of the trades have a solid reputation for producing skilled workers. Performance-oriented 
degree programs in the fine arts (voice, acting, dance, piano, etc.) as well as sports programs from a number of schools get very high marks. The well-known medical and nursing school programs also have earned respect as have a number of commercial-flight and driving programs. The U.S. military also has a predictable track record of transforming recruits into impressive military professionals. There is plenty of evidence that it is possible to effectively and efficiently create job-ready professional, but most schools and corporations just do not have either the interest or wherewithal to make the investment.

\subsection{When educational institutions take-on the responsibility}

Educational institutions have had some success at producing job-ready professionals, but the implementation approaches that tend to work best are not what most schools are willing to do. Teaching hospitals are unlike what most schools offer with their professional masters programs. Most schools try to address the skill and professional behavior deficits of their students through lecture and test-based courses and by means of internships, extra- and co-curricular activities, practicums, and summer jobs. When these things are done well, real value can be delivered. Unfortunately, as evidenced by the current skills gap, most do not do this well.

Internships, similar to OJT, required individuals within the firm to provide an environment conducive to learning, experimenting, and practicing. It is also crucial that the interns receive timely feedback by role-model-worthy professionals who have been properly trained and have the skills and behaviors required. Most firms are just not willing to make the investments required for internship programs to be consistently successful. Even in those cases where the firms might be open to providing such an environment, few faculty members have sufficient insight or true industrial experience to know what should be done, how to do it, or how to develop the workers in the firm to the point of proficiency.

It is common for schools to point to extra- and co-curricular activities as the vehicles necessary and able to deliver the required outcomes. In reality, however, the outcomes of these activities are often unpredictable because the programs do not require specific outcomes and there are no guarantees that the experiences of the students truly address and develop the skills and behaviors needed. If the experiences have not been designed to be complimentary in order to address the whole transformation and are not managed to ensure that each student realizes the needed benefits from the experiences, results will be random.

Practicums and summer jobs have the same issues. They tend to be just as unpredictable and of questionable value. The name of an experience and the fact that one offers it does not make it effective. It is possible for such programs to be consistently successful only when designed and led by experienced academic and business professionals who collaborate effectively and demand specific, relevant outcomes. Unfortunately, this is not the norm.

Moreover, educators find themselves conflicted. Their employment contracts are very specific about promotion, tenure, and contract renewals. At most colleges and universities, publications and research grants are much more highly valued than teaching competency. The more accomplished the professor, the less time they spend instructing students. And real industrial or commercial experience is rarely valued.

Schools are also disadvantaged because there really are no benefits to the schools for producing graduates with job ready skills over just producing graduates. The income to the school is the same ${ }^{13}$ and the job-ready-skills requirement elevates the costs. Moreover, the one thing that schools do have control over (the curricula) is not really at the heart of the skills gap problem. The issues are really more about how the curricula is implemented and delivered by the faculty.

\subsection{When employers and educators partner}

When employers and educators partner effectively, good things tend to happen. Boeing's Learning Together Program ${ }^{14}$ is typical of programs used to encourage lifelong learning. It is also common to see large employers establishing research centers and facilities near major universities.

But again, the magic is in the leadership engagement and performance details. Such partners mutually providing leaders to serve on steering committees, advisory boards, and on red-teams can bring real value to both organizations as well as to the students/employees. Similarly, having expert input into research agendas and major development efforts in schools and commercial firms can bring critically fresh and innovative ideas that are

\footnotetext{
${ }^{13}$ Many schools have fixed credit hour tuition schedules, so it can be difficult to charge more for programs that cost more.

14 http://www.boeing.com/boeing/careers/collegecareers/learning programs.page
} 
just what is needed. Research collaborations and joint efforts to fund highly visible and dynamic initiatives have been successful in creating value.

Building on successes from other domains, apprenticeships, internships, and practicum projects are typical experiences these partnerships might employ. To help launch them, it is common for firms to donate expensive specialized equipment and tools to schools with the expectation they will be used by the students to help them develop the skills the firm needs, and by these experiences the students will want to work for the firm. Firms also have the notion that they will come to know the students and will be in a better position to attract and hire the best. During the honeymoon phase in such initiatives, there is a sincere belief that the school and the employer will fully engage and invest in the partnership, the education and training processes, and reap the rewards of better programs and hiring outcomes.

As with most things, the concept can be simple and compelling, but the implementation is not. Very few partnerships enjoy long-term success. Many of these programs are designed for the elite, do not scale-up well, and tend to be very expensive. A successful collaboration with an "Ivy League" school for training senior executives is seldom a viable solution for training all new managers. There are usually limits on the number of candidates such programs can handle, the content is typically aimed at experienced and more mature executives, and it is not clear that the content or the methods used to deliver it would be appropriate for early or mid-career individuals. When universities try to scale programs in order to support larger numbers of employees, the result often tends to be "Death by PowerPoint", with a primary focus on knowledge transfer as opposed to the development of actual jobready skills. Considering few college and university faculty members have significant real-world, team-oriented industrial experience, this is not a surprise.

Moreover, partnership mechanisms depend on both partners making fundamental shifts in what and how the desired results are to be accomplished. As much as deans, department heads and program coordinators might wish to have their curricula aligned with what businesses need, those who are actually charged with the design, implementation, operation and sustainment of the curricula are seldom involved or interested in such alignments. Tenured faculty members are rewarded and promoted by processes divorced from such alignment and the nontenured (teaching) faculty members do not have the political clout necessary to sufficiently influence the process.

The culture of most commercial firms is necessarily driven by tactical performance measures. As such their commitment to long-term strategic partnerships with educational institutions tends to wane during especially economic downturns. As a result, it is nearly impossible for the two sides to design a mutually rewarding, sustainable partnership because neither side can begin to understand how to find a win-win compromise.

\subsection{What truly works?}

We can gain an understanding of what truly works by exploring why teaching hospitals, apprenticeships, performing arts programs and military training do so effective to develop job-ready graduates.

In a CNN interview on July 7, 2011 Warren Buffett said, "I could end the deficit in five minutes. You just pass a law that says that any time there's a deficit of more than three percent of GDP, all sitting members of Congress are ineligible for re-election. ... now you've got the incentives in the right place, right?"

First, a critical element of all successful training programs is the alignment of trainer/trainee incentives. Top medical and nursing programs are assessed primarily on their graduates' abilities to acquire the necessary certifications and licenses. Drill instructors understand their very lives may depend upon the level of instruction they are providing to their recruits. Coaches will be fired if their athletes are not properly prepared and their teams do not win. And pilot training programs could face liability for a pilot error-related accident if subsequently determined that the training was deficient.

Contrast this with typical undergraduate degree programs where a recent graduate in the first year on the job proceeds to fail in a particularly unfortunate way. There are no real consequences for the faculty or the school that educated the failed employee because colleges and universities make no guarantees that these graduates are actually prepared for life beyond college. Instead, professor advancement and college reputations are typically based upon publications and research grants - not student outcomes.

Second, successful programs are those that immerse the learner in an environment that will seem familiar and understandable when they transition into the working world. Consider the flight simulators that are truly amazing in their ability to make you believe the experience is real - including the need to use an airsickness bag. Teaching hospitals require interns and residents to treat real patients with real conditions and illnesses, and deal with the 
consequences, positive or negative. Performing arts students are required to perform in front of live audiences. Football teams practice outside during adverse weather conditions, even if it is much more comfortable inside, because players need to learn to play in real-game conditions.

Moreover, the proper learning environment includes mentoring and coaching by role-model-worthy professionals who can help students learn and appreciate what it means to be a professional and how to behave under pressure. Students must be taught to be aware of their performance and to reflect upon and assess what is working well and what needs improvement. And it is the nature of most critical work today that it be accomplished by members of high-performance teams, not lone individuals. Understanding the use of team-building processes, methods and tools is critical to creating job-ready professionals.

\subsection{Our solution to the skills gap problem}

Our solution is not a silver bullet that transforms, without significant investments and changes, entire underperforming organizations into high-quality super competitors. Like perpetual motion machines, such silver bullets are very desirable, but they violate fundamental laws that are well known to those who have taken the time to study what others have done and reflect on their own experiences.

The problem we are facing can be characterized by the story of two men; each with a single oar, perpetually stuck trying to get to the other side of a lake. Try as they might with their single oars, each knows the best they would be able to do is row in circles. Now one might conclude that the solution is for the two men to get together so they can leverage two oars and cross the lake effectively. What has been ignored and can only be seen by stepping back and looking more holistically is that while each has an oar, neither has a boat.

We believe the true root cause of the skills gap is a fundamental failure of leadership in both the business and academic communities. Both fail to recognize or fail to sufficiently implement any of the many solutions that exist. So while tools exist to address the skills gap issue (i.e. oars), with some exceptions neither business nor academia has made a serious commitment to solve the problem (i.e. no boat). And without a serious commitment (i.e. a boat) no proposed solution will be successful (i.e. get us to the other side of the lake).

Therefore, addressing the skills gap problem begins with a recognition by both business and academic leaders that they must accept and drive fundamental changes to their organizations (business and academia), changes to the roles played (including their own roles), and changes to the major processes, methods, and tools employed to educate or train their students and employees. ${ }^{15}$ Such commitment, by both business and academia, will tend to insure the existence of long-term partnerships. These partnerships are essential because, while educational institutions have a comparative advantage in educating students, it is business that has the real-world understanding of the ever-changing requirements of job-ready graduates.

As described earlier, these partnerships should include each party providing leaders to serve on steering committees, advisory boards, and on red-teams of the other. Similarly, expert input into research agendas and major development efforts in schools and commercial firms can lead to critically fresh and innovative ideas. Research collaborations and joint efforts to fund highly visible and dynamic initiatives will also create value.

Well developed and professionally led internships and practicum projects in real-world environments will provide value to both partners and will lead to more job-ready graduates.

Moreover, while colleges and universities will better serve their students by regularly updating their curricula, we believe it is even more important that they update their teaching pedagogy. Access to information is no longer the problem to be solved. Instead, educational institutions must assist their students in filtering information and focusing on what is truly important. And then, beyond explaining what that information means, instructors must describe how it is use, applied and implemented in order to create real value.

\footnotetext{
${ }^{15}$ Leaders are often not interested in making such holistic changes, assuming they even agree they are needed. Such transformations take too long in a market place that demands immediate results. So they press ahead with tactics $d u$ jour to hire, train and retain knowledge workers. A few of which are truly new, but most are just minor variations on things that have failed before. The nature of this problem is described in the book, Reengineering the Corporation by Hammer and Champy. But it was not until follow-on books by each (Reengineering Management by Champy and Beyond Reengineering by Hammer) that the fundamental root changes required were actually addressed. Henry Mintzberg's The Rise and Fall of Strategic Planning and Peter Senge's The Fifth Discipline describe the role organizational leaders must play to create critical processes within large organizations to meet near-term performance objectives without compromising long-term goals. An in depth analysis of and solution to this problem is beyond the scope of this paper.
} 
It is most effective to describe the implementation process in an environment that is as close to the real-world as possible. Students interested in curing cancer should be given every opportunity to work in a real laboratory engaged in efforts to cure cancer. Students interested in financial management should be working with local businesses to address their financial issues.

Traditional colleges and universities have a tremendous opportunity to add value to their students and set themselves apart from the crowd by updating their curricula and teaching pedagogy to better match the requirements of today's workplace. Moreover, we believe that those educational institutions that do not change and adapt accordingly will not survive. This process has already begun, albeit at an unacceptably slow pace.

Therein lies the conundrum. Businesses tend to more readily embrace change, but typically lack the expertise to effectively train their workforce. Colleges and universities have a comparative advantage in training and education, but are often resistant to change and do not have the systemic infrastructure or capacity to immerse students in real-world scenarios.

As a result, we are now seeing the development of private sector training enterprises. The current growth of such enterprises, while still somewhat nascent, is evidence of their increasing value relative to traditional education by the markets. For example, coding boot camps" are proliferating rapidly in pursuit of a myriad of opportunities.

For-profit education and training enterprises are beginning to fill the skills gap as traditional colleges and universities struggle to meet the requirements of a fast-changing modern workplace. The ultimate value and success of any enterprise designed to help fill the skills gap, regardless of their for-profit or not-for-profit status, will be determined by the ability to implement and sustain the following learning ecosystem.

Learning experiences led by seasoned educators who:

- Have broad and deep experiences beyond academics in either the private or governmental sectors,

- Are trained mentors in contrast to trained lecturers,

- Can appropriately assess student achievement of realistic professional competencies. That is, to assess student abilities to genuinely demonstrate professional insight and performance in contrast with assessing short-term knowledge retention.

- Are systemically incented to develop well-defined high-quality student learning outcomes, and

- Are held accountable for the students' abilities to effectively demonstrate these learning outcomes.

Learning environments that will provide:

- Immersive experiences that replicate real-world experiences as closely as possible,

- Access to sophisticated professional quality tools and methodologies,

- Opportunities for repetitive practice to develop domain familiarity, consistency and quality performance, and

- Opportunities for thoughtful reflection to develop students' abilities to link and construct valuable meaning from their experiences.

Curricular Delivery Formats that are

- Architected to assure achievement of the stated learning outcomes through a structured learning process,

- Require the development of strong teaming skills,

- Balanced compilations of powerful synchronous and asynchronous activities that can be engaged seamlessly across time and geographical bounds,

- Supported by the best available learning process management technologies, and

- Appropriately scheduled to allow students to master complex topics while being responsive to complicated lives.

\subsection{Conclusion}

A skills gap, resulting from a mismatch of talents possessed by and abilities required of developing workers and recent graduates, threatens the long-term growth of the global economy. The skills gap is especially apparent and concerning for knowledge workers whose main contribution to the economy is knowledge.

The traditional understanding of the skilled labor market and the source of a labor shortage does not consider the "economic wedge" that exists between wages received by employees and the actual costs paid by the employers. The latter includes the direct and indirect costs borne by the employer to provide additional training to new employees. 
The economic wedge is a product of (1) traditional colleges and universities not being structured, incented, or resourced to respond to specific market needs in terms of developing job-ready professionals and (2) businesses (except for a few elite companies) not being structured or equipped to sustain effective internal education and training programs. As such, neither the business community nor the academic community are positioned or moving aggressively enough to address the skills gap.

It is well recognized that partnerships between academia and business could provide effective mechanisms for producing job-ready professions. Such partnerships are attractive because colleges and universities have a comparative advantage in training and education, but often lack the experience to understand the job-ready requirements of employers. Businesses understand their needs but typically lack the resources to effectively train their workforce. Attempts at these partnerships rarely meet their intended goals and are generally not sustainable due to the level of commitment, restructuring and investment required from both academia and business.

A long-term solution first requires recognition by leaders in both business and academia of the depth of the problem combined with significant commitments by leaders in both business and academia to long-term risksharing partnerships. Most notably, sustaining successful partnerships will require significant shifts in how education is traditionally perceived and delivered; including shifts in institutional and programmatic missions, policies and procedures, educational theory, pedagogy, the role of faculty, and most importantly how success is evaluated and measured in terms of student learning outcomes.

Because traditional educational institutions are generally resistant to change, it will be highly problematic for them to successfully realign systemic incentives and to restructure curricular pedagogy to create sufficiently immersive experiences that can produce job ready professionals. As such, market forces are currently driving the growth of private sector education and training enterprises. The success of these organizations in helping to close the skills gap will be based directly on their ability to produce graduates that meet the needs of the markets. It is the opinion of the authors that significant opportunities exist where private sector education and training enterprises will serve as a bridge partner between academia and business by leveraging the strengths and covering the shortcomings of each community. 